\title{
The effects of condensed tannins derived from senescing Rhizophora mangle leaves on carbon, nitrogen and phosphorus mineralization in a Distichlis spicata salt marsh soil
}

\author{
Qiu-Fang Zhang • Hendrikus J. Laanbroek (D)
}

Received: 2 May 2018 / Accepted: 31 August 2018/Published online: 21 September 2018

(C) The Author(s) 2018

\begin{abstract}
Background and aims Due to global warming, it is to be expected that mangroves will move north- and southwards and enter salt marshes, which will then be enriched with mangrove-derived organic compounds. Little is known about the effects that tannins, which are abundantly present in leaf litter of Rhizophora mangle, will have on the biogeochemical cycles in salt marsh soils.

Methods In microcosms, soil from a Distichlis spicata salt marsh was enriched with $R$. mangle-derived leaf powder (LP), crude condensed tannins (CCT) and
\end{abstract}

Responsible Editor: Zucong Cai.

Electronic supplementary material The online version of this article (https://doi.org/10.1007/s11104-018-3807-2) contains supplementary material, which is available to authorized users.

Q.-F. Zhang

College of Oceanology and Food Science, Quanzhou Normal University, 398 Donghai Street, Quanzhou 362000, China

Q.-F. Zhang · H. J. Laanbroek

Department of Microbial Ecology, Netherlands Institute of Ecology (NIOO-KNAW), Droevendaalsesteeg 10, 6708

PBWageningen, The Netherlands

\section{Q.-F. Zhang}

Fujian Province Key Laboratory for the Development of Bioactive Material from Marine Algae, Quanzhou 362100, China

\section{H. J. Laanbroek $(\bowtie)$}

Ecology and Biodiversity Group, Department of Biology, Utrecht University, Padualaan 8, 3584 CHUtrecht, The Netherlands e-mail: r.laanbroek@nioo.knaw.nl purified condensed tannins (PCT), or with commercially available tannic acid (TA). Each treatment received a fixed amount of tannins, i.e. $10 \mathrm{mg} / \mathrm{g}$ dry soil. Due to the enrichment with tannins in each fraction, the amount of carbon added increased from $\mathrm{C}<\mathrm{TA}=\mathrm{PCT}<\mathrm{CCT}$ $<$ LP. At Day 7, 21, 35 and 42 of the incubation period, $\mathrm{CO}_{2}$ emission rates were determined after closing the microcosms for $24 \mathrm{~h}$. Net nitrogen and phosphorous mineralization rates were also determined for the entire incubation period. Experiments were done at Practical Salinity Units of 20,28 and 35 to cover the range in salinities observed in the field ( 20 and 35 PSU).

Results For the whole incubation period, the $\mathrm{CO}_{2}$ emission increased significantly $(p<0.05)$ in the order of $\mathrm{C}$ $<\mathrm{PCT}<\mathrm{CCT}=\mathrm{TA}<\mathrm{LP}$ microcosms. The microcosms with LP showed immobilization of mineral nitrogen and phosphorus, while the other microcosms revealed net nitrogen and phosphorus mineralization in the order of $\mathrm{CCT}<\mathrm{TA}<\mathrm{PCT}<\mathrm{C}$ for $\mathrm{N}$ mineralization, and $\mathrm{CCT}=$ $\mathrm{TA}<\mathrm{C}<\mathrm{PCT}$ for $\mathrm{P}$ mineralization. The $\mathrm{C}$ and $\mathrm{N}$ mineralization rates measured at a salinity of 20 PSU were significantly larger than at 28 and 35 PSU.

Conclusion The results showed that mangrove leaf litter stimulated net $\mathrm{C}$ mineralization and $\mathrm{N}$ and $\mathrm{P}$ immobilization. Purified condensed tannins of senescing $R$. mangle leaves enhanced $\mathrm{C}$ and $\mathrm{P}$, and suppressed net $\mathrm{N}$ mineralization.

Keywords Global warming · Mangrove · Salt marsh · Rhizophora mangle Distichlis spicata $\cdot \mathrm{CO}_{2}$ emission . Nitrogen mineralization $\cdot$ Phosphorus mineralization 


\section{Introduction}

Mangrove forests have been identified as highly productive ecosystems and the most carbon-rich forests on an aerial base in the tropics (Donato et al. 2011), occupying only $0.5 \%$ of the global coastal area but contributing to $10-15 \%$ of the coastal sediment carbon storage (Alongi 2014). Leaves represent one of the most important components of net primary production in mangrove ecosystems (Alongi et al. 2005), thereby providing abundant carbon, nitrogen and phosphorus sources to these coastal ecosystems (Alongi 2012, 2014; Bouillon et al. 2008; Dittmar et al. 2006; Hernes et al. 2001; Kristensen et al. 2008).

Due to global warming, $R$. mangle is expected to migrate into intertidal wetlands that are currently dominated by herbaceous species (Bianchi et al. 2013; Comeaux et al. 2012; Gabler et al. 2017; Saintilan et al. 2009; Saintilan et al. 2014); thereby potentially altering nutrient cycling patterns. Tannins are abundantly present in vascular plant tissues (Hernes et al. 2001), including species of the Rhizophoraceae, which contain especially large amounts of tannins (Basak et al. 1999; Hernes et al. 2001; Hernes and Hedges 2004). The percentage of extractable condensed tannins amounted to $21.9 \%$ of the dry weight of $R$. mangle leaves (Zhang et al. 2010), and tannins plus other phenolic compounds accounted for $18 \%$ of the dissolved organic matter in $R$. mangle leachate (Benner et al. 1990). In contrast to mangroves, herbaceous intertidal wetland species such as Distichlis spicata, which is a widespread species in intertidal wetlands in North America (Hauser 2006), contains 0.3 and $0.1 \%$ of total free phenolics and tannins, respectively, of the dry weight (Shajeela et al. 2011). Since the production of total phenolics and tannins by salt marsh grasses such as D. spicata, is low compared to R. mangle, the expansion of this mangrove species into salt marshes dominated by $D$. spicata should result in an increase in the levels of total phenolics and tannins in the soil. We hypothesized that the migration of $R$. mangle into intertidal salt marshes in response to climate change will affect the cycles of carbon, nitrogen and phosphorus due to the enrichment of the soil with tannins, which have widely been considered as regulators of nutrient cycles (Hattenschwiler and Vitousek 2000; Hernes et al. 2001; Kraus et al. 2003).

Several underlying mechanisms for the impacts that tannins have on nutrient cycling have been proposed (Kraus et al. 2003; Kraus et al. 2004; Nierop et al. 2006b; Verkaik et al. 2006). For example, tannins can reduce the activity and growth of soil microbes, can inhibit the activity of microbial exo-enzymes, and can form complexes with protein-containing organic matter making it more resistant to decomposition (Bradley et al. 2000; Fierer et al. 2001; Kraus et al. 2004; Schimel et al. 1996). However, low concentrations of tannins might also increase the coiled structures of the enzymes boosting their catalytic activity (Adamczyk et al. 2017). Phosphorus assimilation by microorganisms can be restricted by tannins due to competition for binding sites such as aluminum, iron and their oxides (Northup et al. 1998). Hydrolyzable tannins (HTs) are made of sugar cores, to which gallic or hexahydroxydiphenic acids are ester-linked. Compared to condensed tannins (CTs), HTs can serve as immediate $\mathrm{C}$ sources thereby immobilizing $\mathrm{N}$ and $\mathrm{P}$ (Nierop et al. 2006a). The commercially available tannic acid, a type of HT composed of a glucose unit to which gallic acid is bound, has often been selected as an appropriate standard for the purpose of quantification of nutrient dynamics in soils (Kraus et al. 2003; Kraus et al. 2004; Nierop et al. 2006a; Nierop et al. 2006b). The CTs are composed of mixtures of polymers of flavan-3-ol units with different degrees of polymerization and mostly hydroxyl substitutions, including dihydroxylated procyanidin (PC) and trihydroxylated prodelphinidin (PD) monomers (Maie et al. 2003). In nearly senescent, yellow-colored leaves of $R$. mangle the ratio of PC and PD monomers amounted to 9:1 (Maie et al. 2003). PC monomers are generally more stable than PD monomers (Hernes et al. 2001).

To test the hypothesis that the migration of $R$. mangle with a high content of condensed tannins and PC monomers in its senescing leaves will affect the cycles of carbon, nitrogen and phosphorus in D. spicata dominated salt marsh soils, we mixed the soil of a $D$. spicata salt marsh in microcosms with tannins originating from senescing leaves from $R$. mangle and measured the emission of $\mathrm{CO}_{2}$ and the mineralization of nitrogen and phosphorus.

\section{Materials and methods}

Collection of senescing Rhizophora mangle leaves and salt marsh soil

Senescing yellow-colored leaves were hand-picked from Rhizophora mangle trees in Saint Lucie County, 
Florida, USA, and soil from a Distichlis spicata dominated salt marsh was collected from the Merritt Island National Wildlife Refuge $\left(28^{\circ} 42^{\prime} 31.58^{\prime} \mathrm{N}\right.$, $80^{\circ} 44^{\prime} 16.16^{\prime} \mathrm{W}$, Brevard County, Florida, USA), in March 2015. The collected leaves were air dried. The Merritt Island wetland was the site of an experiment, in which seedlings of $R$. mangle were planted in an area dominated by D. spicata (Laanbroek et al. 2018).

Soil samples used in this study were collected as part of the experiment described in (Laanbroek et al. 2018) and have the following characteristics. The fresh soil has a mean $\mathrm{pH}_{\mathrm{KCl}}$ of 7.5, a moisture content of $87 \%(w / \mathrm{w})$ and a salinity of 20 PSU (Laanbroek et al. 2018). Total carbon, total nitrogen and total phosphorus content of the soil was $30.45 \mathrm{mg} \mathrm{C}, 2.13 \mathrm{mg} \mathrm{N} \mathrm{g}^{-1}$ and $0.24 \mathrm{mg} \mathrm{P}$ $\mathrm{g}^{-1}$ dried soil, respectively. The contents of $\mathrm{NH}_{4}^{+}$, $\mathrm{NO}_{3}{ }^{-}, \mathrm{PO}_{4}{ }^{3-}$ in $2 \mathrm{M} \mathrm{KCl}$ extracts were $145.05 \mathrm{mg} \mathrm{N}$, $0.00 \mathrm{mg} \mathrm{N}$ and $36.08 \mathrm{mg} \mathrm{P}$ per kilogram dried soil, respectively. The amounts of total tannins (TT), total phenolics (TP) and hydrolyzable tannins (HT) were $3.93 \mathrm{mg}$ TAE (tannic acid equivalent), $5.29 \mathrm{mg}$ TAE and $6.41 \mathrm{mg}$ MEG (methyl gallate equivalent) per gram dried soil, respectively.

A subset of the soil samples used in the study of (Laanbroek et al. 2018) were stored at $4{ }^{\circ} \mathrm{C}$ prior to use in this experiment. The leaves of $R$. mangle used in this experiment were senescing (i.e., they had started to turn yellow) and were hand-picked from the trees and air-dried. Some of the air-dried leaves were used for extraction and purification of condensed tannins (description below) and others were ground, sieved through a $0.26 \mathrm{~mm}$ mesh screen and mixed with soil before the start of the incubation experiment described below.

Extraction and purification of condensed tannins

After cleaning the air-dried leaves with distilled water, condensed tannins (CT) were extracted and purified using published methods (Lin et al. 2006; Zhou et al. 2012). The ground, dried leaves were extracted with acetone-water (70: 30), the extract was filtered through a Buchner funnel with a vacuum pump and concentrated by vacuum-rotary evaporation. A solution of crude condensed tannins (CCT) was obtained after extracting the residue with n-hexane three times. The CCT solution was freeze-dried and stored at $-20^{\circ} \mathrm{C}$ for further purification of condensed tannins and for use in the soil microcosms.

Part of the freeze-dried CCT extract was dissolved in a solution of $50 \%$ methanol-water $\left(\mathrm{V}_{\mathrm{CCT}} / \mathrm{V}_{\text {solution, }} 1: 1\right)$ and loaded on a Sephadex LH-20 column, eluted with approximately $2 \mathrm{~L}$ of the $50 \%$ methanol-water solution to remove low molecular weight phenolics and flavonoid compounds, and then eluted with $200 \mathrm{~mL}$ of an acetone-water (70: 30 ) solution to remove the bonded tannin fraction from the column. Finally, purified condensed tannins (PCT) were obtained by vacuum-rotary evaporation and freeze-drying. The PCT fraction was stored at $-20{ }^{\circ} \mathrm{C}$ for use in the soil microcosms.

Nutrient characteristics of leaf powder and condensed tannins fraction

The weight percentage of PCT in the CCT fraction and in the dried $R$. mangle leaves was 30.4 and $13.40 \%$, respectively. The carbon content of the different tannin fractions was determined with an EA/110 elemental CN analyzer (InterScience BV, Breda, The Netherlands), while the nitrogen and phosphorus contents of these fraction were measured with a Skalar SA-40 auto analyzer (InterScience BV, Breda, The Netherlands). The carbon, nitrogen and phosphorus contents of the leaf powder (LP) amounted to $422.09,4.54$ and $0.24 \mathrm{mg} \mathrm{g}^{-1}$ dry material, respectively. The $\mathrm{C}, \mathrm{N}$ and $\mathrm{P}$ contents of the CCT were 439.37, 2.82 and $0.12 \mathrm{mg} \mathrm{g}^{-1}$ dry material, respectively, and the $\mathrm{C}, \mathrm{N}$ and $\mathrm{P}$ contents of the PCT were 543.52, 0.65 and $0.07 \mathrm{mg} \mathrm{g}^{-1}$ dry material, respectively.

\section{Soil microcosm incubation experiment}

The soil microcosms consisted of fresh soil samples at the equivalent of $5 \mathrm{~g}$ dry soil contained in $500 \mathrm{ml}$ screwcap bottles that can be closed with a silicon rubber inlay. Since condensed tannins are not produced in isolation by $R$. mangle, but in a mixture with other carbon compounds, we decided to study the effects of $R$. manglederived tannins in a series of carbon sources from $R$. mangle leaves with increasing purity of tannins, i.e. powder-milled leaves, crude CTs and purified CTs. In addition to these $R$. mangle-derived carbon sources, we tested also the effects the commercially available tannic acid. At the start of the incubation period, the soil samples were enriched with the different sources of tannins: leaf powder from $R$. mangle (LP), crude condensed tannins from $R$. mangle leaves (CCT), purified condensed tannins from $R$. mangle leaves (PCT), and commercial tannic acid (TA) (Sigma-Aldrich Co, St. Louis, MO, USA, Molecular Weight 1701.20, 
$\mathrm{C}_{76} \mathrm{H}_{52} \mathrm{O}_{46}$ ) representing hydrolyzable tannins (Nierop et al. 2006b). One part of the soil microcosms that served as control (C) did not receive tannins.

Since the salinity in the $D$. spicata salt marsh was variable between years (Laanbroek et al. 2018) and since salinity might play a role in nutrient dynamics during mangrove decomposition (Contreras et al. 2017), we performed the experiment at different salinity levels of 20, 28 and 35 PSU, respectively. 20 and 35 PSU were the extremes of the salinities observed in the field (Laanbroek et al. 2018). Sodium chloride was added to the soil microcosms to attain the desired salinity levels. Each treatment and salinity level were replicated five times resulting in 75 microcosms in total.

All soil samples were pre-incubated for 7 days at $25{ }^{\circ} \mathrm{C}$ at $80 \%$ moisture content to allow microbial activity to stabilize before the experiment started. According to a previous study (Kraus et al. 2004), a concentration of $10 \mathrm{mg}^{2}$ tannins $\mathrm{g}^{-1}$ dry soil can be considered as an ecologically realistic amount of tannins in $R$. mangle leaves. Therefore, the pre-incubated LP, CCT, PCT and TA microcosms with $5 \mathrm{~g}$ dry soils each received 373 , 164, 50 and $50 \mathrm{mg}$ of $R$. mangle leaf powder, crude condensed tannins, purified condensed tannins, and tannic acid, respectively, and the tannins-enriched soils were mixed thoroughly. The microcosms were then incubated for 42 days in a dark room at a temperature of $25^{\circ} \mathrm{C}$ and $80 \%$ moisture content. Bottles were loosely closed with screw-caps to prevent suboxic conditions and large fluctuations in moisture content. Soil moisture content was controlled weekly and when necessary corrected by adding water.

Quantification of $\mathrm{CO}_{2}$ emission

$\mathrm{CO}_{2}$ emission measurements were carried out at Day 7 , 21,35 and 42 after the start of the experiment. Three out of five bottles of each treatment were randomly selected, and the screw-caps were closed for $24 \mathrm{~h}$ at the day of sampling. Gas samples were taken at 0 and $24 \mathrm{~h}$ with a syringe, transferred into a vacuumed and sealed glass tube of $25 \mathrm{~mL}$ and stored at $20^{\circ} \mathrm{C}$ in a dark room before the determination of $\mathrm{CO}_{2}$.

$\mathrm{CO}_{2}$ concentrations were measured on a GC-FID (Trace GC-Ultra, Thermo Scientific Inc., Waltham USA) equipped with a methanizer (Interscience Scientific, Breda, The Netherlands). $250 \mu \mathrm{L}$ headspace sample was injected with a splitter (split ratio 4.2), and eluted with helium 5.0 at a flow of $5.0 \mathrm{~mL} \mathrm{~min}^{-1}$ at isotherm $50^{\circ} \mathrm{C}$. The column was a $30 \mathrm{~m} 0.32 \mu \mathrm{m}$ RT-QBond (Restek, Cat Number 19744). The FID was set at $350{ }^{\circ} \mathrm{C}$ with a $\mathrm{H}_{2}$-flow of $35 \mathrm{~mL} \mathrm{~min}^{-1}$, an air-flow of $350 \mathrm{~mL} \mathrm{~min}^{-1}$ and a $\mathrm{N}_{2}$-make-up-flow of $10 \mathrm{~mL} \mathrm{~min}^{-1}$. Data was acquired with the Chromeleon 7.2 software package (Thermo Scientific Inc., Waltham, USA). Peak identification and quantification by one-point calibration was based on 1200 ppm $\mathrm{CO}_{2} 3.0$ in synthetic air (Westfalen, Deventer, the Netherlands). The retention time of $\mathrm{CO}_{2}$ was $0.99 \mathrm{~min}$.

\section{Determination of soil properties}

After completing $\mathrm{CO}_{2}$ gas collection at Day 42, soil samples were taken from the microcosms for further analysis. For the determination of soil physicochemical properties, the soil samples were extracted by shaking for $1 \mathrm{~h}$ with a $2 \mathrm{M} \mathrm{KCl}$ solution (soil: $\mathrm{KCl}$ solution = 2: $3, w / \mathrm{w}$ ), after which $\mathrm{pH}$ was measured. The solutions were filtered through filter paper and subsequently centrifuged at $5000 \mathrm{~g}$ for $15 \mathrm{~min}$. The supernatants were analyzed for $\mathrm{NH}_{4}{ }^{+}, \mathrm{NO}_{2}{ }^{-}, \mathrm{NO}_{3}{ }^{-}$and $\mathrm{PO}_{4}{ }^{3-}$ by a Quaatro Seal autoanalyzer (Beun-De Ronde, Abcoude, The Netherlands). The differences in the amounts of $\mathrm{NH}_{4}{ }^{+}+\mathrm{NO}_{2}{ }^{-}+\mathrm{NO}_{3}{ }^{-}$, and in the amount of $\mathrm{PO}_{4}{ }^{3-}$ measured at the start and at Day 42 of incubation were considered as nitrogen and phosphorus net mineralization in the soils.

Determination of total phenolics, total tannins and hydrolyzable tannins

Total phenolics, total tannins and hydrolyzable tannins in the soils were determined at the end of the incubation experiment. The total phenolics (TP) content in the soil was determined according to a previously published, but slightly modified method (Asami et al. 2003; Morita 1980; Northup et al. 1995). After extraction of the soil with a sodium pyrophosphate solution, the TP content was determined in a colorimetric assay with FolinCiocalteu reagent at $760 \mathrm{~nm}$. The results are presented in milligrams of tannic acid equivalents (TAE) per gram soil. The total tannins (TT) content was determined according to a previously published method (Adamczyk et al. 2008). The results are also given in milligrams of tannic acid equivalents (TAE) per gram soil. The amounts of hydrolyzable tannins (HT) in soils were determined according to a previously published, but slightly modified method (Adamczyk et al. 2008; 
Hartzfeld et al. 2002). Methyl gallate was used as standard and the results are given in milligrams of methyl gallate equivalents (MGE) per gram soil.

Statistical analysis

All statistical analyses were performed using the SPSS software package (version 22.0; SPSS Statistics Inc., Chicago, IL). Spearman Rank Order correlation analysis was performed between soil physicochemical properties, total phenolics (TP), total tannins (TT), hydrolyzable tannins (HT) and net $\mathrm{N}$ and $\mathrm{P}$ mineralization in samples collected at Day 42, and total $\mathrm{CO}_{2}$ emission, which was estimated by assuming a $\mathrm{CO}_{2}$ emission for week 1 and 2 of the incubation being equivalent to the rate measured at Day 7, plus a $\mathrm{CO}_{2}$ emission for week 3 and 4 being equivalent to the rate measured at Day 21, plus a $\mathrm{CO}_{2}$ emission for week 5 being equivalent to the rate measured at Day 35, plus a $\mathrm{CO}_{2}$ emission for week 6 being equivalent to the rate measured at Day 42. After the Shapiro-Wilk test for normal distribution and the Levene's Test of Equality of Error Variances, two-way ANOVAs were used to assess significant effects of the treatments (including the control), and of the three salinities concentrations on pore water $\mathrm{pH}$, total phenolics (TP), hydrolyzable tannins (HT), total tannins (TT) of soils, net $\mathrm{N}$ and $\mathrm{P}$ mineralization, $\mathrm{CO}_{2}$ emission at Days 7, 21, 35, 42 and total $\mathrm{CO}_{2}$ emission. Two-way ANOVAs were also used to assess significant effects of individual treatments on the total estimated $\mathrm{CO}_{2}$ emission during the period of 42 days. Significant differences between treatments and salinities have been tested by application of Tukey's Post Hoc tests in General Linear Models. A simple effect test based on twoway ANOVA (Braver et al. 2005) was carried out to assess the impact of tannin sources and salinity on soil properties, $\mathrm{CO}_{2}$ emission and net $\mathrm{N}$ and $\mathrm{P}$ mineralization. The level of statistical significance for all tests was set at $P<0.05$.

\section{Results}

The impact of Rhizophora mangle-derived tannins and salinity on soil $\mathrm{pH}$

Treatment and salinity had both a significant effect $(P=$ 0.000 for both) on soil $\mathrm{pH} 42$ days after the start of the experiment (Table 1, Supplementary Tables 1a, b, c). A two-way ANOVA showed that soil $\mathrm{pH}$ was also significantly affected by the interaction of treatment and salinity $(P=0.007$, Supplementary Table 1a). Among all treatments, the addition of leaf powder resulted in significantly $(P<0.05)$ higher $\mathrm{pH}$ values, followed by the other treatments in the order $\mathrm{C}>\mathrm{CCT}=\mathrm{PCT}>\mathrm{TA}$ (Supplementary Table 1b). Soil $\mathrm{pH}$ was significantly different between the three salinities with 35 PSU $>28$ PSU $>20$ PSU (Supplementary Table 1c). A simple effect test based on two-way ANOVA showed that treatments significantly $(P<0.05)$ affected soil $\mathrm{pH}$ at each salinity level, but salinity had no effect on the $\mathrm{pH}$ within one treatment (not shown).

The impact of Rhizophora mangle-derived tannins and salinity on $\mathrm{CO}_{2}$ emission rates

$\mathrm{CO}_{2}$ emission rates varied with treatment, salinity and time of measurement, i.e. Day 7, 21, 35 or 42 (Fig. 1, Supplementary Tables 2, 3a, b, c). Each time $\mathrm{CO}_{2}$ emission rates were measured, there was a significant $(P<0.05)$ difference between treatments in the order of LP $>$ CCT $>$ TA $>$ PCT $>$ C (Supplementary Table 3b). Only on Days 21 and 42, $\mathrm{CO}_{2}$ emission rates measured in the presence of crude condensed tannins and of tannic acid did not differ significantly from each other. On Day 21 , the $\mathrm{CO}_{2}$ emission rates in the PCT treatment and controls did also not differ significantly. With the exception of at Day 7, the $\mathrm{CO}_{2}$ emission rates at $20 \mathrm{PSU}$ were always significantly $(P<0.05)$ higher than at the other two salinities and the emission rates were not significantly different from each other at the two higher salinities (Supplementary Table 3c). A simple effect test based on two-way ANOVA showed that on each measurement day treatment significantly $(P<0.05)$ affected the $\mathrm{CO}_{2}$ emission rate at each salinity level, whereas salinity had no influence on the $\mathrm{CO}_{2}$ emission rate within each treatment (not shown).

Time had a significant effect on the $\mathrm{CO}_{2}$ emission rates (Fig. 1, Supplementary Table 4a). In all treatments, except in the control, the $\mathrm{CO}_{2}$ emission rates on Day 7 were significantly $(P<0.05)$ higher than on later measuring days (Fig. 1, and Supplementary Table $4 \mathrm{~b}$ ). The $\mathrm{CO}_{2}$ emissions in the LP and CCT treatments continued to decrease after Day 7, although the decrease in the last week of the experiment was not significant anymore. The $\mathrm{CO}_{2}$ emissions in the PCT treatment halted after Day 7 as no significant changes were observed after that day. The $\mathrm{CO}_{2}$ emission in the TA treatment decreased 


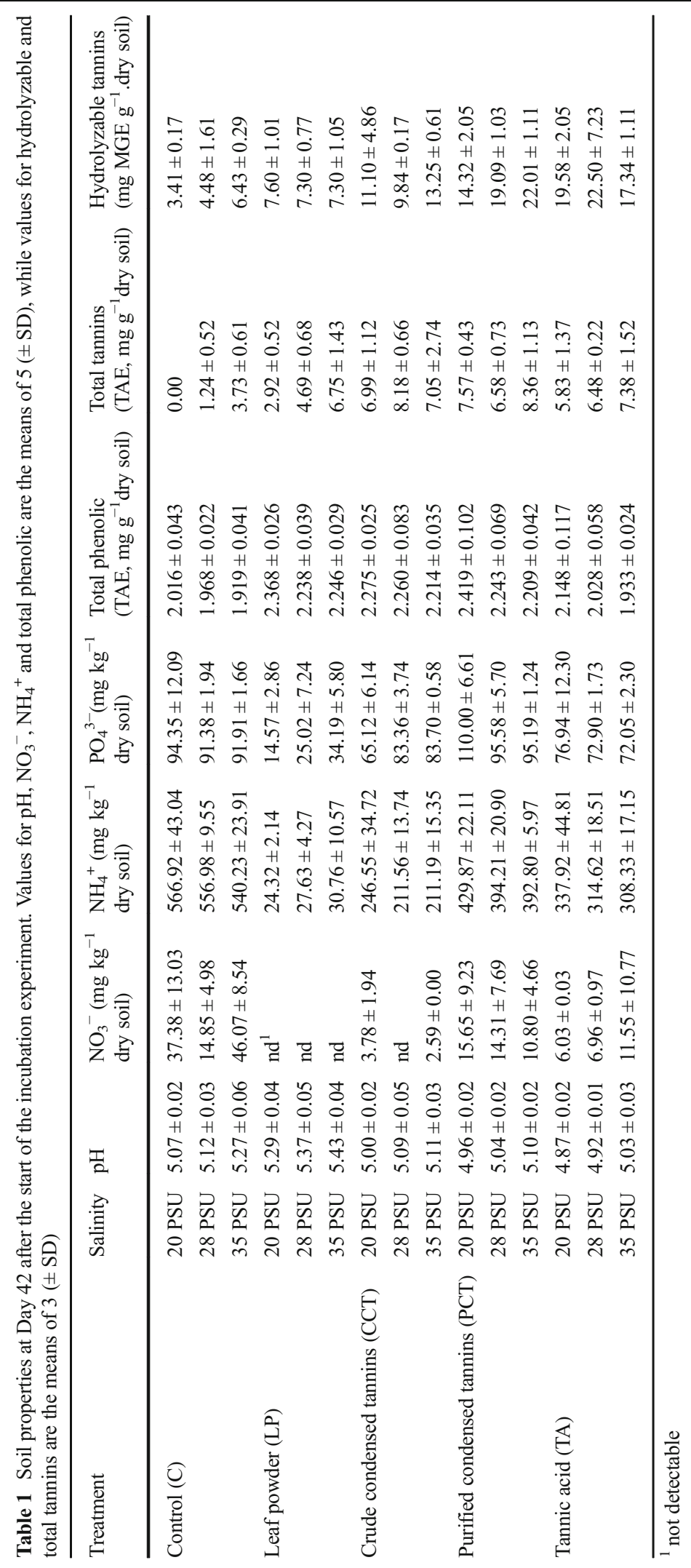




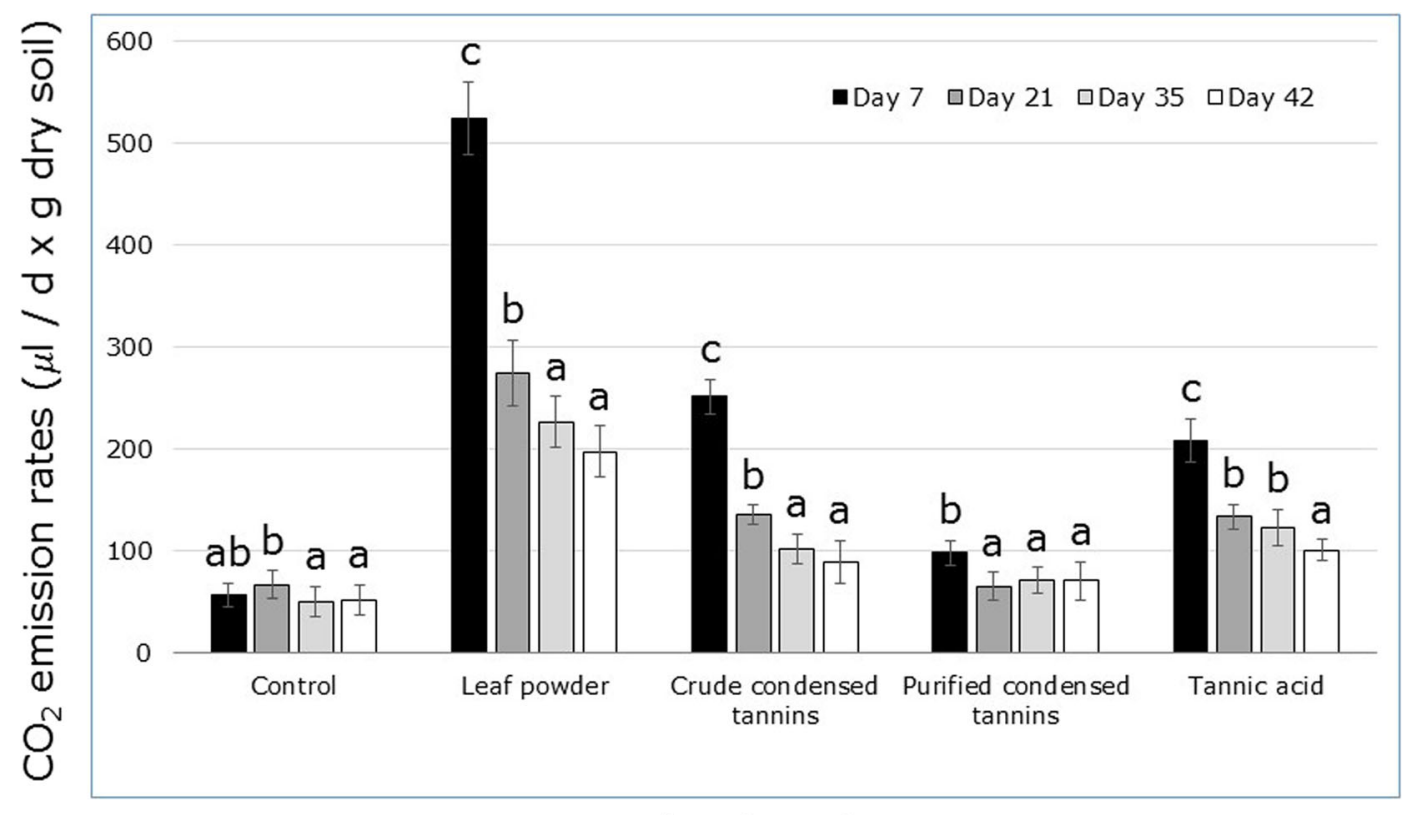

\section{treatment}

Fig. 1 Average $\mathrm{CO}_{2}$ emission rates measured at Day 7 (black bars), Day 21 (dark gray bars), Day 35 (light gray bars) or Day 42 (white bars) in microcosms containing Distichlis spicata salt marsh soils enriched with different organic fractions derived from Rhizophora mangle leaves or with tannic acid (called treatments).

significantly till the end of the experiment. The $\mathrm{CO}_{2}$ emission in the control started to decrease significantly at Day 35.

The $\mathrm{CO}_{2}$ emission rates in the control and in the LP treatments were significantly $(P<0.05)$ higher at a salinity of 20 PSU than at a salinity of 35 PSU (Supplementary Table $4 \mathrm{c})$, whereas the rates in the PCT treatment were significantly $(P<0.05)$ higher at a salinity of 20 than at salinities of 28 and 35 PSU. No significant effects of salinity were observed for the CCT and the TA treatments (Supplementary Table 4c).

The impact of Rhizophora mangle-derived tannins on total $\mathrm{CO}_{2}$ emission

The cumulative amount of emitted $\mathrm{CO}_{2}$ estimated during the 42 days incubation period varied with treatment, salinity and time of measurement (Fig. 2, Supplementary Table 1a). For the $\mathrm{CO}_{2}$ accumulation estimated for the whole incubation period, the $\mathrm{CO}_{2}$ production with leaf powder added was significantly $(P<0.05)$ higher than other treatments, followed by $\mathrm{CCT}=\mathrm{TA}>\mathrm{PCT}>\mathrm{C}$ (Fig. 2 and Supplementary Table 1b), while the cumulative $\mathrm{CO}_{2}$ emission at a salinity of 20 PSU was
The averages comprise all the data measured at salinities of 20, 28 and 35 PSU. Error bars represent standard errors $(n=3)$. Different characters indicate significant differences $(\mathrm{p}<0.05)$ between the measuring days within a treatment. The effects of salinity are presented in Supplementary Table 3c

significantly $(P<0.05)$ higher than at salinities of 28 and 35 PSU (Supplementary Table 1c). A simple effect test based on two-way ANOVA showed that treatment significantly $(P<0.05)$ affected the cumulative $\mathrm{CO}_{2}$ emission at each salinity level, whereas salinity has still no significant influence on the cumulative $\mathrm{CO}_{2}$ emission within each treatment (not shown).

The impact of Rhizophora mangle-derived tannins and salinity on nitrogen mineralization

The concentrations of $\mathrm{NH}_{4}{ }^{+}$and $\mathrm{NO}_{3}{ }^{-}$in soil samples collected on Day 42 varied with treatment and salinity (Table 1). $\mathrm{NO}_{2}^{-}$was only detected at a level of 3$4 \mathrm{mg} \mathrm{N} \mathrm{kg}^{-1}$ dry soil in a few soil samples in the control or PCT treatment. Net Nitrogen mineralization $\left(\mathrm{N}_{\mathrm{MIN}}\right)$ (Fig. 3) was significantly affected by treatment $(P=0.000)$ and salinity $(P=0.000)$ (Supplementary Table 1a). Only the LP treatment had negative $\mathrm{N}_{\mathrm{MIN}}$ values. The treatment with leaf powder was the only one in which nitrogen immobilization occurred and net nitrogen mineralization was observed in the other treatments. The amounts of mineralized nitrogen increased significantly $(P<0.05)$ with $\mathrm{CCT}<\mathrm{TA}<\mathrm{PCT}<\mathrm{C}$ (Fig. 




Fig. 2 Average cumulative $\mathrm{CO}_{2}$ emission during a period of 42 days in microcosms containing Distichlis spicata salt marsh soils enriched with different organic fractions derived from Rhizophora mangle leaves or with tannic acid (called treatments). The cumulative $\mathrm{CO}_{2}$ emission has been estimated from Fig. 1. The averages comprise all the data measured at salinities of 20, 28 and 35 PSU. Error bars represent standard errors $(n=3)$. Different characters indicate significant differences $(p<0.05)$ between the treatments. The effects of salinity are presented in Supplementary Table 1c

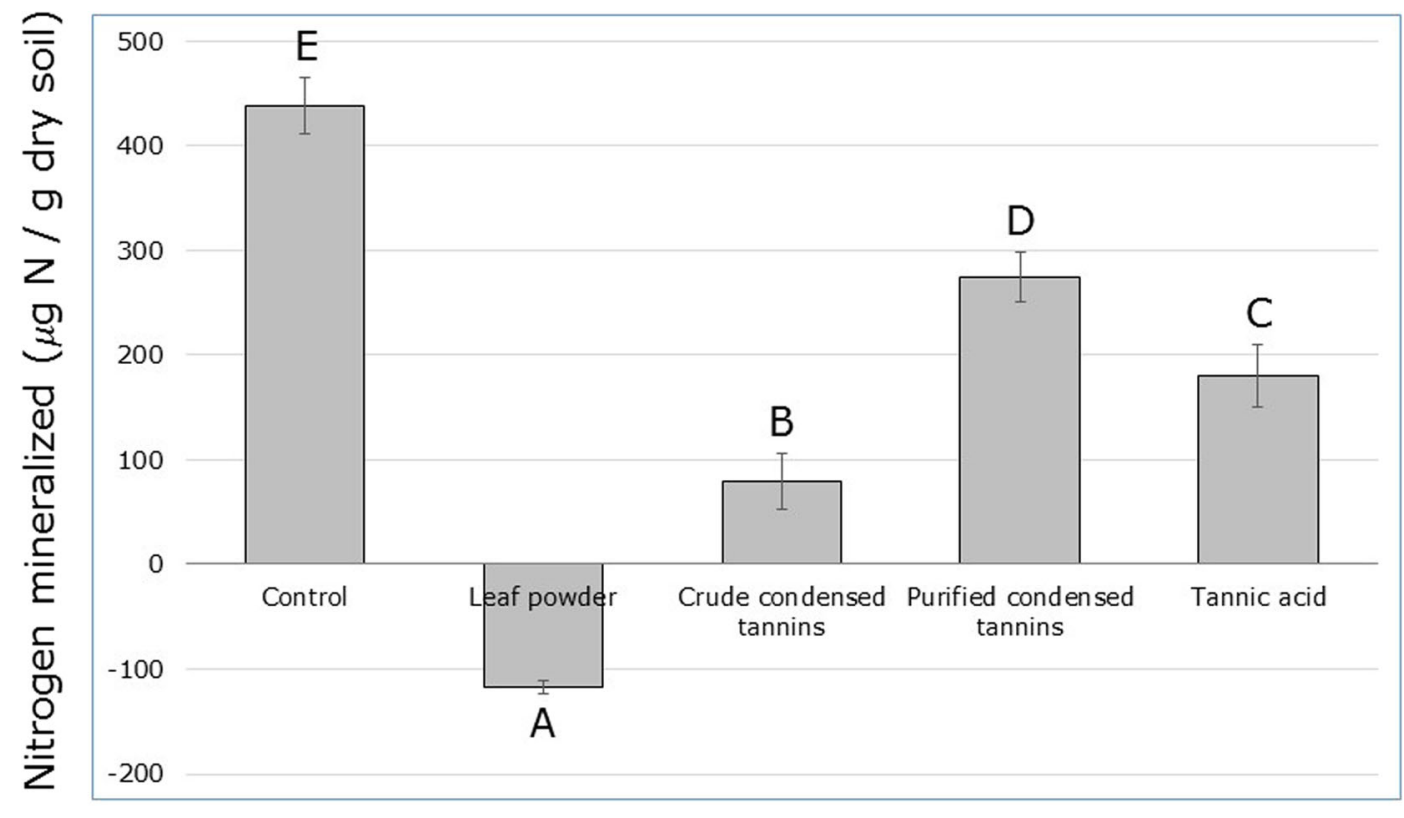

\section{treatment}

Fig. 3 Average nitrogen mineralization during a period of 42 days determined in microcosms containing Distichlis spicata salt marsh soils enriched with different organic fractions derived from Rhizophora mangle leaves or with tannic acid (called treatments). The averages comprise all the data measured at salinities of 20, 28 and 35 PSU. Error bars represent standard errors $(n=5)$. Different characters indicate significant differences $(p<0.05)$ between the treatments. The effects of salinity are presented in Supplementary Table 1c 
3 and Supplementary Table $1 b$ ). $\mathrm{N}_{\text {MIN }}$ in the soil with 20 PSU was significantly higher compared to soils incubated with 28 and 35 PSU (Supplementary Table 1c). A simple effect test based on two-way ANOVA showed that treatments significantly $(P<0.05)$ affected $\mathrm{N}_{\mathrm{MIN}}$ at each salinity level, but salinity had no significant effect on $\mathrm{N}_{\mathrm{MIN}}$ within one treatment (not shown).

The impact of Rhizophora mangle-derived tannins and salinity on phosphorus mineralization

The $\mathrm{PO}_{4}{ }^{3-}$ concentration (Table 1 ) and net $\mathrm{P}$ mineralization $\left(\mathrm{P}_{\mathrm{MIN}}\right)$ (Fig. 4) on Day 42 varied with treatment and salinity. A two-way ANOVA showed that $\mathrm{P}_{\mathrm{MIN}}$ was significantly affected by treatment $(P=0.000$, Supplementary Table $1 \mathrm{~b})$ and by the interaction between treatment and salinity $(P=0.000)$, but not by the salinity itself $(P=0.173)$. In contrast to the other treatments, the incubation with leaf powder, similar to $\mathrm{N}$, resulted in phosphorus immobilization. The amounts of mineralized $\mathrm{P}$ increased significantly $(P<0.05)$ in the order $\mathrm{TA}=\mathrm{CCT}<\mathrm{C}<\mathrm{PCT}>$ (Fig. 3 and Supplementary Table 1b). No significant differences in $\mathrm{P}_{\mathrm{MIN}}$ were observed between 20 PSU, 28 PSU and 35 PSU
(Supplementary Table 1c). As shown by a simple test based on two-way ANOVA, treatments significantly $(P<0.05)$ affected $\mathrm{P}_{\mathrm{MIN}}$ in the soils at each salinity level, but salinity did not affect $\mathrm{P}_{\mathrm{MIN}}$ within one treatment (not shown).

The impact of treatment and salinity on phenolics and tannins dynamics

Total phenolics and total and hydrolyzable tannins on day 42 are shown in Table 1. There were significant effects of treatment and salinity on total phenolics (2way ANOVA; $P=0.000$, Supplementary Table 9$)$, total tannins ( $P=0.000$ for treatment, $P=0.006$ for salinity) and hydrolyzable tannins $(P=0.000$ for treatment). Salinity had no significant effect on hydrolyzable tannins $(P=0.084)$, whereas the interactive effect of treatment and salinity was significant for total phenolics, total tannins and hydrolyzable tannins $(P=0.018$, $P=0.014$ and $P=0.028$, respectively).

The individual differences in total phenolics, total tannins and hydrolyzable tannins among treatments at Day 42 are listed in Supplementary Table 5b. Total phenolics differed significantly $(P<0.05)$ in the order

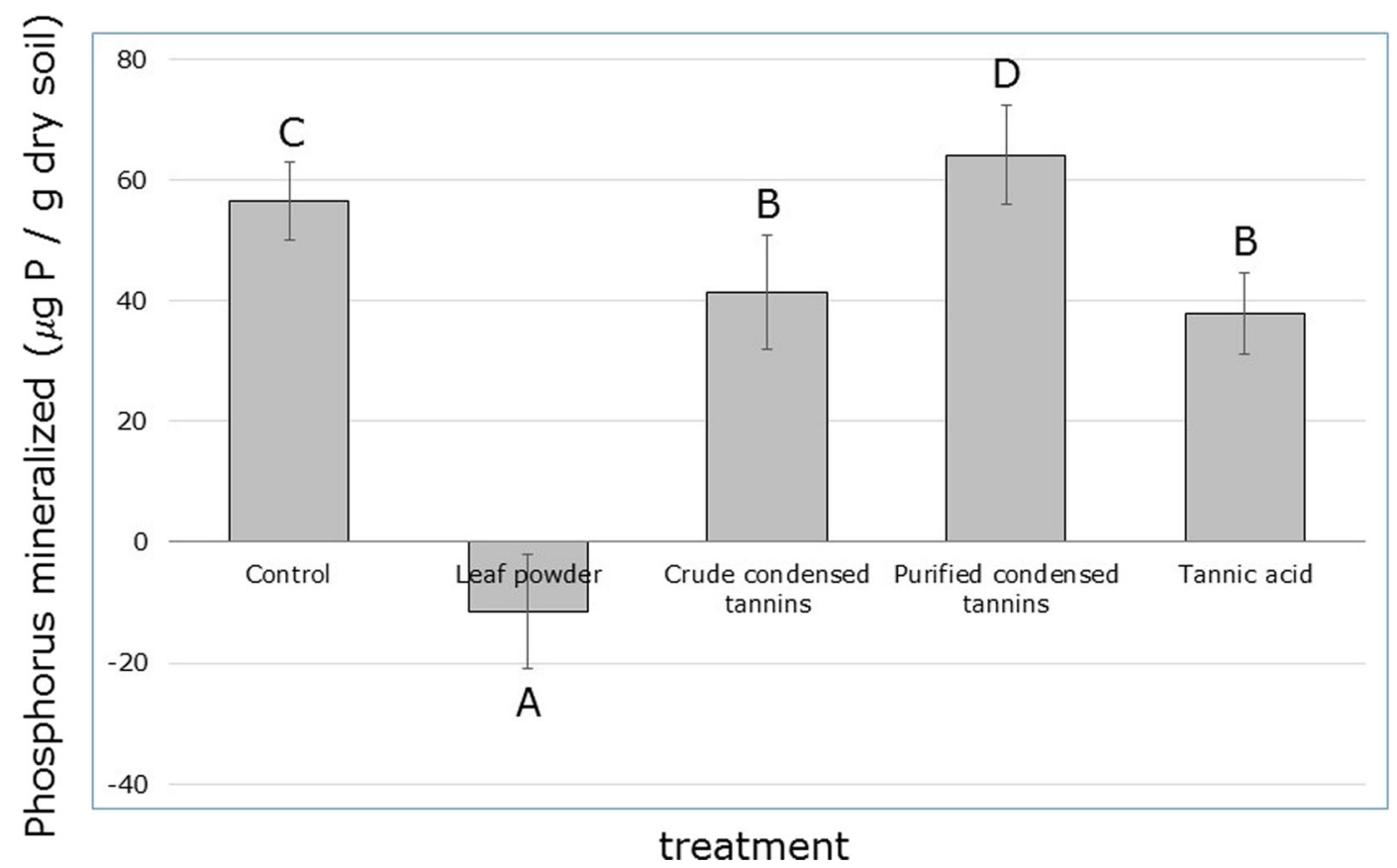

Fig. 4 Average phosphorus mineralization during a period of 42 days determined in microcosms containing Distichlis spicata salt marsh soils enriched with different organic fractions derived from Rhizophora mangle leaves or with tannic acid (called treatments). The averages comprise all the data measured at salinities of 20, 28 and 35 PSU. Error bars represent standard errors $(n=5)$. Different characters indicate significant differences $(p<0.05)$ between the treatments. The effects of salinity are presented in Supplementary Table 1c 
$\mathrm{C}<\mathrm{TA}<\mathrm{CCT}=\mathrm{LP}=\mathrm{PCT}$. The amounts of total phenolics increased significantly $(P<0.05)$ with salinity in the order of 35 PSU $<28$ PSU $<20$ PSU. Total tannins increased significantly $(P<0.05)$ in the different treatments in the order of $\mathrm{C}<\mathrm{LP}<\mathrm{TA}=\mathrm{CCT}=\mathrm{PCT}$. While total tannins at 35 PSU were significantly $(P<0.05)$ higher than at $20 \mathrm{PSU}$, total tannins at $28 \mathrm{PSU}$ was not significantly different from the other salinity levels. The amounts of hydrolyzable tannins increased significantly $(P<0.05)$ in the different treatments in the order of $\mathrm{C}=$ $\mathrm{LP}<\mathrm{CCT}<\mathrm{PCT}=\mathrm{TA}$. Salinity had no significant effect on the amounts of TA at the end of the incubation period. Simple effect tests based on ANOVA showed that treatments significantly $(P<0.05)$ affected the amounts of total phenolics, total tannins and hydrolyzable tannins in the soil samples at each salinity level, but salinity had no significant effect on the amounts of total phenolics, total tannins and hydrolyzable tannins in the soil samples of each treatment (not shown).

Interactions between $\mathrm{C}, \mathrm{N}$ and $\mathrm{P}$ mineralization and soil characteristics

Spearman Rank Order correlations between soil properties, net $\mathrm{N}$ and $\mathrm{P}$ mineralization in soil samples at Day 42 , and total $\mathrm{CO}_{2}$ emission during the 42-day incubation period are shown in Supplementary Table 6. As shown in Figs. 2, 3 and 4, the estimated $\mathrm{C}$ mineralization, or total $\mathrm{CO}_{2}$ emitted during the incubation period was significantly and negatively $(P=0.000)$ correlated with $\mathrm{N}$ and $\mathrm{P}$ mineralization (Spearman's rho values -0.912 and -0.815 , respectively), while $\mathrm{N}$ and $\mathrm{P}$ mineralization were mutually significantly and positively correlated $(P=0.000$, Spearman's rho value 0.795$)$. Net $\mathrm{N}$ and $\mathrm{P}$ mineralization were significantly $(P=0.000)$ and positively correlated with $\mathrm{NH}_{4}{ }^{+}, \mathrm{NO}_{3}{ }^{-}, \mathrm{PO}_{4}{ }^{3-}$ (Spearman's rho values between 0.721 and 1.000 ), while $\mathrm{C}$ mineralization was significantly $(P=0.000)$ and negatively

Table 2 Calculated pools of carbon, nitrogen and phosphorus (mg / g dry soil) in the different organic fractions present in Distichlis spicata salt marsh soils and in Rhizophora mangle leaves: $\mathrm{SOM}=$ Soil organic matter, $\mathrm{LPF} 1=$ leaf powder - crude correlated with these nutrients (Spearman's rho values $-0.914,-0.830$, and -0.815 , respectively). Total remaining phenolics was significantly $(P=0.002)$ and positively correlated with C mineralization (Spearman's rho value 0.447 ), and negatively with net $\mathrm{N}$ mineralization and $\mathrm{NH}_{4}{ }^{+}$and $\mathrm{NO}_{3}{ }^{-}(P=0.000$, Spearman's rho values $-0.484,-0.474$, and -0.339 , respectively). Remaining total and hydrolyzable tannins, which were mutually significantly and positively correlated $(P=$ 0.000 , Spearman's rho value 0.613 ), were not significantly correlated with one of the other factors, except total remaining tannins with total remaining phenolics $(P=0.042$, Spearman's rho value 0.304$)$. Soil $\mathrm{pH}$ correlated significantly and positively with salinity, but negatively with $\mathrm{NH}_{4}{ }^{+}, \mathrm{PO}_{4}{ }^{3-}$, total tannins, hydrolyzable tannins, net $\mathrm{N}$ and $\mathrm{P}$ mineralization.

Potentially available $\mathrm{C}, \mathrm{N}$, and $\mathrm{P}$ for mineralization in the organic fractions from the leaves

Knowing the carbon, nitrogen and phosphorus contents of the added organic fractions derived from $R$. mangle (see the Materials and Methods section) and knowing the amounts of organic fractions added to the salt marsh soils, the amounts of carbon, nitrogen and phosphorus that are potentially available for mineralization could be calculated (Table 2). In Table 2 we have defined four organic fractions, i.e. the soil organic matter (SOM), the organic fraction only present in leaf powder (LPF1), the fraction present in leaf powder and crude condensed tannins (LPF2) and the fraction present in leaf powder and in the crude and purified condensed tannins (LPF3). Assuming a conservative use of SOM, meaning no stimulation by the presence of organic compounds present in the other organic fractions (priming), then the amounts of SOM respired in the different treatments are the same as in the control (Table 3). In the same way, the conservative use of carbon in the different

condensed tannins, LPF2 $=$ crude condensed tannins - purified condensed tannins, LPF3 = purified condensed tannins, and TA = tannic acid

\begin{tabular}{llllll}
\hline Organic fraction & SOM & LPF1 & LPF2 & LPF3 & Fraction's total \\
\hline Carbon pool & 30.450 & 17.065 & 8.988 & 5.435 & 67.938 \\
Nitrogen pool & 2.130 & 0.246 & 0.086 & 0.007 & 2.468 \\
Phosphorus pool & 0.240 & 0.018 & 0.004 & 0.001 & 0.263 \\
\hline
\end{tabular}


Table 3 Conservatively estimated carbon, nitrogen and phosphorus mineralization ( $\mathrm{mg} / \mathrm{g}$ dry soil) in the different organic fractions present in Distichlis spicata salt marsh soils and in
Rhizophora mangle leaves (see Table 2 for explanation) in 42 days after addition of leaf powder, crude condensed tannins, purified condensed tannins or tannic acid

\begin{tabular}{|c|c|c|c|c|c|c|}
\hline Organic fraction & SOM & LPF1 & LPF2 & LPF3 & TA & Fraction's total \\
\hline \multicolumn{7}{|l|}{ Carbon mineralization } \\
\hline Control & 1.314 & & & & & 1.314 \\
\hline Leaf powder & 1.314 & 3.962 & 1.857 & 0.447 & & 7.580 \\
\hline Crude condensed tannins & 1.314 & & 1.857 & 0.447 & & 3.618 \\
\hline Purified condensed tannins & 1.314 & & & 0.447 & & 1.761 \\
\hline Tannic acid & 1.314 & & & & 2.093 & 3.408 \\
\hline \multicolumn{7}{|l|}{ Nitrogen mineralization } \\
\hline Control & 0.438 & & & & & 0.438 \\
\hline Leaf powder & 0.438 & -0.197 & -0.196 & -0.163 & & -0.117 \\
\hline Crude condensed tannins & 0.438 & & -0.196 & -0.163 & & 0.079 \\
\hline Purified condensed tannins & 0.438 & & & -0.163 & & 0.275 \\
\hline Tannic acid & 0.438 & & & & -0.259 & 0.180 \\
\hline \multicolumn{7}{|l|}{ Phosphorus mineralization } \\
\hline Control & 0.056 & & & & & 0.056 \\
\hline Leaf powder & 0.056 & -0.053 & -0.023 & 0.008 & & -0.011 \\
\hline Crude condensed tannins & 0.056 & & -0.023 & 0.008 & & 0.041 \\
\hline Purified condensed tannins & 0.056 & & & 0.008 & & 0.064 \\
\hline Tannic acid & 0.056 & & & & -0.019 & 0.038 \\
\hline
\end{tabular}

fractions can be calculated. Considering the treatment with added leaf powder, $17 \%$ of the $\mathrm{CO}_{2}$ emission is then accounted for by the soil organic carbon, $52 \%$ by the LPF1 fraction (i.e. the organic compounds only present in the treatment with leaf powder), $25 \%$ by the LPF2 fraction (i.e. the organic compounds present in the treatments with leaf powder and crude condensed tannins) and $6 \%$ by LPF3 fraction (i.e. the organic compounds present in the treatments with leaf powder and crude and purified condensed tannins). The calculated carbon availabilities in the different organic fractions were $45,25,13$ and $8 \%$ for SOM, LPF1, LPF2, and LPF3, respectively. Hence, the estimated use of carbon in relation to its availability was low with the SOM and the LPF2 fraction, high with the LPF1 fraction and approximately equal with the LPF3 fraction. The latter is surprising considering the presence of high molecular weight, condensed tannins in the LPF3 fraction. However, the LPF3 fraction contained also organic compounds of lower molecular weight as discussed above. In the treatment with tannic acid, $39 \%$ of the $\mathrm{C}$ respired in the treatment was calculated to originate from SOM and $61 \%$ from tannic acid, while the availability of carbon in these sources amounted to 85 and $15 \%$, respectively.

\section{Discussion}

The responses of $\mathrm{CO}_{2}$ emission and nitrogen and phosphorus mineralization rates to the addition of Rhizophora mangle-derived leaf powder and its condensed tannins to salt marsh soils showed that the intrusion of R. mangle into salt marshes may impact $\mathrm{C}, \mathrm{N}$ and $\mathrm{P}$ dynamics through the addition of leaf litter alone. The results demonstrated that different fractions of organic matter derived from $R$. mangle leaf litter can have a significant effect on $\mathrm{C}, \mathrm{N}$ and $\mathrm{P}$ mineralization. Purified condensed tannins stimulated $\mathrm{C}$ and $\mathrm{P}$ mineralization, but repressed $\mathrm{N}$ mineralization. Leaf powder produced from dried $R$. mangle leaves contained other organic compounds besides condensed tannins and it stimulated $\mathrm{C}$ mineralization, but repressed $\mathrm{N}$ and $\mathrm{P}$ mineralization. The difference in behavior of leaf powder and purified condensed tannins especially in relation to net $\mathrm{N}$ 
mineralization must be due to differences in the quantities of carbon added and the quality of the applied material, i.e. organic leaf components other than condensed tannins.

\section{Carbon mineralization}

The increased $\mathrm{CO}_{2}$ emission rates observed in all treatments showed that with one exception, i.e. the PCT treatment at day $21, \mathrm{CO}_{2}$ respiration was stimulated by the experimental additions. The $\mathrm{CO}_{2}$ emission rates were in the order $\mathrm{C}<\mathrm{PCT}<\mathrm{TA}<\mathrm{CCT}<\mathrm{LP}$, although the differences in total $\mathrm{CO}_{2}$ emitted over the period of 42 days were not significant between the TA and CCT treatments. The increasing amounts of $\mathrm{CO}_{2}$ emitted from purified condensed tannins via crude condensed tannins to leaf powder can largely be explained by the increasing amounts of $\mathrm{C}$ present in the distinct additions in the microcosms.

$\mathrm{CO}_{2}$ production during a relatively short period of 42 days as applied in our incubation experiment, may have been mainly due to oxidation of leaf compounds such as sugars, but also other labile compounds like organic acids, proteins and phenols may have contributed to the gas production (Davis et al. 2003; Valiela et al. 1985).

The structure of condensed tannins isolated from $R$. mangle by Zhang and colleagues, who did also the isolation of condensed tannins for our study, showed large heterogeneities in the degree of polymerization, the pattern of hydroxylation, and the substitution with monosaccharides (Zhang et al. 2010). Condensed tannin oligomers mixtures consisted of procyanidin and prodelphinidin structural units with the former dominating. The purification method used by Zhang and colleagues was similar to the methods used by others for the isolation of condensed tannins from leaves of Balsam poplar (Fierer et al. 2001) and from needles of Scots pine and Norway spruce (Kanerva et al. 2006). While the application of methods used for other plants may not be fully applicable to $R$. mangle, we believe that they are appropriate because the fraction of crude condensed tannins from $R$. mangle resembles the $\mathrm{F} 1$ fraction in the other mentioned publications. This fraction F1 contained only a low percentage of condensed tannins composed of mono- and dimers and relatively large amounts of low molecular weight phenols, flavonoid monomers, sesqui- and diterpenes, and resin acids (Kanerva et al. 2006). The fraction of purified condensed tannins from $R$. mangle corresponds then with the combined F2, F3, F4 fractions of the formerly mentioned studies with Balsam poplar, Scots pine and Norway spruce. The combined F2, F3, F4 fractions consisted of condensed tannins compose of tetra- and hexamers and higher tannin polymers, with lower amounts of mono-and trimers tannins and other compounds of low molecular weight (Fierer et al. 2001; Kanerva et al. 2006). Since the $\mathrm{CO}_{2}$ production from the treatment with crude condensed tannins was significantly higher than the $\mathrm{CO}_{2}$ production from the treatment with purified condensed tannins, it seems likely that this difference in $\mathrm{CO}_{2}$ production was due to the respiration of low weight compounds being more present in the crude condensed fraction. This is consistent with other studies that have shown that light fractions of tannins strongly enhanced respiration (Fierer et al. 2001; Gamble et al. 1996; Grant 1976; Kanerva et al. 2006; Schimel et al. 1996).

$\mathrm{CO}_{2}$ emission from purified condensed tannins was significantly lower than that from tannic acid, as was observed before (Kraus et al. 2004; Nierop et al. 2006b) and was also significantly lower than from crude condensed tannins and leaf powder. However, $\mathrm{CO}_{2}$ emission from purified condensed tannins was significantly higher than the control on all sampling days, except on Day 21. The enhanced $\mathrm{CO}_{2}$ respiration by $\mathrm{CT}$ addition compared to the control at the first days has been observed before with condensed tannins extracted from Balsam poplar (Fierer et al. 2001), Scots pine and Norway spruce (Kanerva et al. 2006) and Corsican pine litter (Nierop et al. 2006b). The same early peak in $\mathrm{CO}_{2}$ emission was noticed in Rhododendron and Huckleberry, which contain a high percentage of PC monomers (Kraus et al. 2004). In contrast, the carbon respiration rates of $\mathrm{CT}$ from Manzanita, Salal and Bishop pine that contain a low percentage of PC monomers were increased not only during the first days but also significantly at the later decomposition stages (Kraus et al. 2004). Hence, the fact that $C$ mineralization varied in our experiment with time, may be due to the composition and structure of condensed tannins extracted from senescing $R$. mangle leaves. PC monomers, comprising more than $80 \%$ of the condensed tannins and consisting of highly polymerized molecules of high molecular weight are more resistant to degrade over time than the smaller, more labile fraction of PD monomers with their higher degree of hydroxylation (Hernes et al. 2001; Zhang et al. 2010). The degree of hydroxylation of PD-extender units enriched in 2,3-trans monomers and of PC-extender units enrich in 2,3-cis monomers was 
considered more important for stability than stereochemistry (Hernes et al. 2001). In short-term experiments, high molecular weight PC tannins were not respired by soil microbes, while low molecular weight polyphenols such as methyl gallate, catechin and hydrolyzable tannins were rapidly respired, with the smaller and less highly cross-linked gallotannins degrading more rapidly (Talbot and Finzi 2008). Therefore, we suggest that the $\mathrm{CO}_{2}$ emitted at the early phase of our experiment was mainly at the expense of some of the $\mathrm{PD}$ monomers with three-hydroxyl groups on the B-ring of the condensed tannins, and at a later stage at the expense of PC monomers with only one or two hydroxyl groups on the B-ring. Additionally, respiration might have been inhibited by complexation of proteinaceous substrates with tannins that will reduce exoenzyme activity (Schimel et al. 1996). The proportion of proteinprecipitating phenolics increases with increasing degree of polymerization of the tannin fractions from Robinia pseudoacacia leaves (Kumar and Horigome 1986), and the ability to precipitate is higher with high molecular than with low molecular weight tannins (Kraus et al. 2003). Therefore, the composition and the structure of condensed tannins will play an important role in respiration in soils. In addition, tannins do not only bind to proteins, but also to other organic nitrogen compounds (Adamczyk et al. 2011; Halvorson et al. 2011).

Low molecular weight organic molecules, which are likely more present in the leaf powder and the crude condensed tannins fraction, may stimulate the degradation of more recalcitrant carbon compounds present in the different organic additions and in the SOM by a process called priming. However, in a study on the effect of glucose on the degradation of peat from Avicennia marina and Rhizophora mucronata, the presence of a priming effect could not be confirmed (Keuskamp et al. 2013) and the same was true for the effect of glucose on peat from $R$. mangle (Keuskamp et al. 2015). Although these results were based on peat from mangrove species, a priming effect of low molecular weight organic molecules on the degradation of more recalcitrant carbon compounds present in mangrove leaf litter and even in salt marsh soils might also be of minor importance.

\section{Nitrogen mineralization}

At the start of the incubation experiment the mineral $\mathrm{N}$ concentrations in the salt marsh soil were $145.05 \mathrm{mg}$
$\mathrm{NH}_{4}{ }^{+}-\mathrm{N}$ and $0.00 \mathrm{mg} \mathrm{NO}_{3}{ }^{-}-\mathrm{N}$ per kg dry soil. $\mathrm{NH}_{4}{ }^{+}$and $\mathrm{NO}_{3}{ }^{-}$concentrations increased in all treatments except in the treatment with leaf powder. $\mathrm{NO}_{3}{ }^{-}$was not detected in the LP treatment and in a few samples of the CCT treatment. $\mathrm{N}_{2} \mathrm{O}$ emission was not detected during the incubation period (data no shown). The loss of mineral $\mathrm{N}$ in the treatment with leaf powder was likely due to immobilization of nitrogen at the expense of the excess carbon added to the soil as was observed in previous studies (Nierop et al. 2006a; Rivera-Monroy and Twilley 1996). The decrease in net $\mathrm{N}$ mineralization observed between the treatments $(\mathrm{C}>\mathrm{PCT}>\mathrm{TA}>$ CCT) was likely due to the increasing availability of carbon in this series (Nierop et al. 2006a) or to an increased inhibition of mineralization of organic $\mathrm{N}$ through complexation by some organic compounds added (Schimel et al. 1992). Hence, added carbon compounds may either stimulate or inhibit $\mathrm{N}$ mineralization. Whereas the smaller compounds may more readily be used as $\mathrm{C}$ source, the larger compounds might become more firmly attached to organic $\mathrm{N}$ compounds, thereby retarding $\mathrm{N}$ mineralization (Fierer et al. 2001). More low molecular weight compounds were provided in the soil with LP, CCT and TA treatment than in the PCT treatment that likely contained a high percentage of PC polymers. Based on the total amount of carbon added, the treatment with PCT containing more complex organic compounds, stimulated $\mathrm{CO}_{2}$ production and net $\mathrm{N}$ mineralization to a limited extend, suggesting that the purified condensed tannins bound to N-containing substrates thereby reducing the $\mathrm{N}$ availability to microbial cell by toxic or protein-precipitating effects. It has been suggested that condensed tannins with a high percentage of PD like tannins from $R$. mangle monomers bind more strongly to proteins and other organic matter, thereby reducing $\mathrm{N}$ mineralization more than condensed tannins with PC monomers.

As shown for carbon, the nitrogen content of the different organic fractions that had been applied to the salt marsh soil in the different treatments were calculated (Table 2). When assuming again a conservative use of organic nitrogen in the different treatments, meaning that the same amount of nitrogen was mineralized from a distinct organic fraction present in a treatment, the amounts of $\mathrm{N}$ utilization can be calculated for each treatment (Table 3). By the high level of net $\mathrm{N}$ mineralization measured in the control, all other calculated $\mathrm{N}$ utilizations in the different organic fractions were negative, meaning immobilization of the mineralized $\mathrm{N}$ into 
microbial cells. In three out of five fractions (i.e. in LPF1, LPF2 and TA) the pool of nitrogen is lower than the amount of nitrogen immobilized. Hence, SOM had to be the source of nitrogen for the immobilization processes in these fractions. In the treatment with leaf powder, the size of $\mathrm{N}$ immobilization in relation to net $\mathrm{N}$ mineralization is that large that overall a net immobilization is observed, while in the other treatments net $\mathrm{N}$ mineralization predominated.

Phosphorus mineralization

Similar to net $\mathrm{N}$ mineralization, net $\mathrm{P}$ mineralization was affected by treatments showing immobilization of $\mathrm{P}$ in the leaf powder treatment, and variable net mineralization in the other treatments. However, with an increasing amount of net $\mathrm{P}$ mineralization in the order of $\mathrm{TA}=$ $\mathrm{CCT}<\mathrm{C}<\mathrm{PCT}$, net $\mathrm{P}$ mineralization differed from net $\mathrm{N}$ mineralization with respect to the differential effects observed in the PCT and C treatments. Whereas net N mineralization showed a significant decrease in the PCT treatment compared to the control, net $\mathrm{P}$ mineralization was significantly increased in the presence of purified condensed tannins. This may have been due to polyphenol binding to sesquioxides, which can prevent phosphate sorption. Phenolic acids have even been shown to desorb from mineral sites and bound phosphate (Davis 1982). The ortho-phenolic groups of tannins are strong competitors for surface sites of $\mathrm{Al}$ and $\mathrm{Fe}$ oxides, where they may replace bound P. As discussed above, a high percentage of PC monomers in condensed tannins will bind to soil organic compounds and consequently lower the carbon availability to soil microorganisms, thereby decreasing their growth capacity and hence their P requirement (Nierop et al. 2006a; Nierop et al. 2006b). Polyphenols can maintain the availability of metal micronutrients (e.g. $\mathrm{Mn}^{2+}, \mathrm{Fe}^{2+}$ and $\mathrm{Cu}^{2+}$ ) by the formation of organic complexes (Schnitzer et al. 1984; Zech et al. 1997). Selection of Eucalyptus trees with a high content of phenolics in their leaves has been suggested for improvement of P availability in Spodosols (Hingston 1963).

As done for carbon and nitrogen, the amounts of phosphorus present in the different organic fractions were calculated (Table 2) as well as the sizes of phosphorus mineralization (Table 3). Net P mineralization is observed in the SOM and in the LPF3 fraction, whereas $\mathrm{P}$ immobilization is shown in the LPF1, LPF2 and TA fractions. In the treatment with leaf powder, the $P$ immobilization processes in the LPF1 and LPF2 organic fractions exceeded the net $\mathrm{P}$ mineralization processes in the SOM and in the LPF3 fraction leading to an overall $\mathrm{P}$ immobilization.

Effect of salinity on $\mathrm{N}$ and $\mathrm{P}$ mineralization and $\mathrm{CO}_{2}$ emission

Salinity is likely one of the important factors to affect nutrient dynamics during decomposition of mangrove litter (Dittmar et al. 2006). Compared to the 28 and 35 PSU salinities, total $\mathrm{C}$ and $\mathrm{N}$ mineralization was higher at 20 PSU (Supplementary Table 1c). The positive effect of low salinity on $\mathrm{C}$ mineralization was most pronounced at the later stages of decomposition (Supplementary Table 3c) as well as in the PCT treatment (Supplementary Table 4c). In contrast, low salinity decreased $\mathrm{C}$ mineralization in the control treatment. Salinity had no impact on P dynamics. Salinity had a significant and positive influence on $\mathrm{pH}$, however it had a negative effect on total phenolics (Supplementary Table 6). This latter might be due to the fact that most of the tannins may have been eliminated from dissolved fractions by absorption to soil particles at all salinity levels applied. This may occur when the salinity levels are higher than 15\%o (Maie et al. 2008). Adsorption of tannins is conditioned at the same time by $\mathrm{pH}$ (Maie et al. 2008) and other soil characteristics, such as the properties of organic matter (Kaiser 2003), the presence of sesquioxides (Kaal et al. 2005; Varadachari et al. 1994), the particle size, and the surface area (Kiem and Kogel-Knabner 2002).

\section{Comparison to the field trial}

The results obtained in the microcosm experiment clearly showed that of $\mathrm{C}, \mathrm{N}$ and $\mathrm{P}$ dynamics varied with the different fractions of organic matter derived from senescing $R$. mangle leaves. The results from adding $R$. mangle leaf powder to the soil, which mimics best leaf litter fall, suggests that there will be ecosystem effects resulting from $R$. mangle intrusion into salt marshes. Carbon mineralization will increase, but nitrogen and phosphorus will be immobilized. The results related to nitrogen confirms the absence of effects of added $R$. mangle leaf litter on the nitrogen-related processes of nitrification and denitrification and on the genes coding for microbial processes in the nitrogen cycle as observed in an earlier field experiment 
(Laanbroek et al. 2018). In this earlier field study, we observed a stimulation of the growth of $R$. mangle seedlings in the presence of added $R$. mangle leaf litter, which seems contradictory to the enhanced nitrogen and phosphorus immobilization observed in the present experiment. However, two things should be kept in mind. First, the difference in timescale between the field experiment and the laboratory experiment (i.e. 4 years and 6 weeks, respectively) and the absence of active plant roots in the laboratory experiment that may interfere with microbial immobilization processes.

Overall, we observed a significant increase in carbon and nitrogen mineralization at a salinity of 20 PSU compared to salinities of 28 and 35 PSU. For phosphorus mineralization we did not see a significant effect of salinity on the mineralization of these elements. In the previous field study by us (Laanbroek et al. 2018), we found that a significant annual difference in soil salinity with average PSU values of 20 and 35 PSU for the years 2015 and 2012, respectively. The difference in salinity between these years was explained by a difference in rain fall in the months preceding the sampling of the soils. With the two microbial processes measured in the field study, nitrification was significantly higher at the lower salinity level as observed during the measurements of $\mathrm{C}$ and $\mathrm{N}$ mineralization in the present microcosm experiment. We conclude that at least some microbial processes seem to be stimulated by lower salinities. The fact that salinity did not affect the denitrification in the field experiment shows that the interaction between microbial conversion rates and salinity involves more soil variables such as the availabilities of oxygen and nitrate in the case of denitrification.

Finally, it is important to mention that the composition of the tannins in the leaves of $R$. mangle changes with the age of the leaves with the smallest tannin polymers disappearing leaving the largest polymers in the most senescent leaves (Kandil et al. 2004). In contrast, total and extractable condensed tannins seem to increase with senescence of the leaves in Rhizophora stylosa (Lin et al. 2010). Hence, it is important to collect the senescing leaves from the trees just before they fall as done by us since these leaves will affect the geochemical cycles in the salt marsh soil.

Acknowledgements We like to acknowledge the support of our colleagues Drs. Jos Verhoeven and Dennis Whigham in collecting the salt marsh soil samples on Merritt Island, Drs. Yong-Mei Wang and Liang-Liang Zhang for extracting and purifying the fractions of condensed tannins from Rhizophora mangle leaves, and $\mathrm{Mr}$.
Gerrit Rouwenhorst for the chemical analysis of these organic fractions. Dennis Whigham is also acknowledged for critically reading the manuscript. The study was supported by a grant from the National Natural Science Foundation of China to Q.-F.Z. (grant no. 41571252). This is publication number 6598 of the Netherlands Institute of Ecology.

Open Access This article is distributed under the terms of the Creative Commons Attribution 4.0 International License (http:// creativecommons.org/licenses/by/4.0/), which permits unrestricted use, distribution, and reproduction in any medium, provided you give appropriate credit to the original author(s) and the source, provide a link to the Creative Commons license, and indicate if changes were made.

\section{References}

Adamczyk B, Kitunen V, Smolander A (2008) Protein precipitation by tannins in soil organic horizon and vegetation in relation to tree species. Biol Fertil Soils 45:55-64. https://doi.org/10.1007/s00374-008-0308-0

Adamczyk B, Adamczyk S, Smolander A, Kitunen V (2011) Tannic acid and Norway spruce condensed tannins can precipitate various organic nitrogen compounds. Soil Biol Biochem 43:628-637. https://doi.org/10.1016/j. soilbio.2010.11.034

Adamczyk B, Karonen M, Adamczyk S, Engstrom MT, Laakso T, Saranpaa P, Kitunen V, Smolander A, Simon J (2017) Tannins can slow-down but also speed-up soil enzymatic activity in boreal forest. Soil Biol Biochem 107:60-67. https://doi.org/10.1016/j.soilbio.2016.12.027

Alongi DM (2012) Carbon sequestration in mangrove forests. Carbon Management 3:313-322. https://doi.org/10.4155 /cmt.12.20

Alongi DM (2014) Carbon cycling and storage in mangrove forests. Annu Rev Mar Sci 6(1):195-219. https://doi. org/10.1146/annurev-marine-010213-135020

Alongi DM, Pfitzner J, Trott LA, Tirendi F, Dixon P, Klumpp DW (2005) Rapid sediment accumulation and microbial mineralization in forests of the mangrove Kandelia candel in the Jiulongjiang estuary, China. Estuar Coast Shelf Sci 63:605618. https://doi.org/10.1012/j.ecss.2005.01.004

Asami DK, Hong YJ, Barrett DM, Mitchell AE (2003) Comparison of the total phenolic and ascorbic acid content of freeze-dried and air-dried marionberry, strawberry, and corn grown using conventional, organic, and sustainable agricultural practices. J Agric Food Chem 51:1237-1241. https://doi.org/10.1021/jf020635c

Basak UC, Das AB, Das P (1999) Organic constituents in leaves of 9 mangrove species of Orissa coast, India. Pak J Bot 31:55-62

Benner R, Weliky K, Hedges JI (1990) Early diagenesis of mangrove leaves in a tropical estuary - molecular-level analyses of neutral sugars and lignin-derived phenols. Geochim Cosmochim Acta 54:1991-2001. https://doi.org/10.1016 /0016-7037(90)90267-o

Bianchi TS, Allison MA, Zhao J, Li XX, Comeaux RS, Feagin RA, Kulawardhana RW (2013) Historical reconstruction of 
mangrove expansion in the Gulf of Mexico: linking climate change with carbon sequestration in coastal wetlands. Estuar Coast Shelf Sci 119:7-16. https://doi.org/10.1016/j. ecss.2012.12.007

Bouillon S, Borges AV, Castaneda-Moya E, Diele K, Dittmar T, Kristensen E, Lee SY, Marchand C, Middelburg JJ, RiveraMonroy VH, Smith TJ III, Twilley RR (2008) Mangrove production and carbon sinks: a revision of global budget estimates. Global Biochemical Cycles 22:1-12. https://doi. org/10.1029/2007GB003052

Bradley RL, Titus BD, Preston CP (2000) Changes to mineral N cycling and microbial communities in black spruce humus after additions of $\left(\mathrm{NH}_{4}\right)_{2} \mathrm{SO}_{4}$ and condensed tannins extracted from Kalmia angustifolia and balsam fir. Soil Biol Biochem 32:12271240. https://doi.org/10.1016/s0038-0717(00)00039-0

Braver SL, Mackinnon DP, Page MC (2005) Levine's guide to SPSS for analysis of variance. L. Erlbaum Associates Inc.

Comeaux RS, Allison MA, Bianchi TS (2012) Mangrove expansion in the Gulf of Mexico with climate change: implications for wetland health and resistance to rising sea levels. Estuar Coast Shelf Sci 96:81-95. https://doi.org/10.1016/j. ecss.2011.10.003

Contreras LM, Fierro-Cabo A, Cintra-Buenrostro CE (2017) Early drivers of black mangrove (Avicennia germinans) leaf litter decomposition in the water column. Hydrobiologia 803:147157. https://doi.org/10.1007/s10750-017-3167-6

Davis JA (1982) Adsorption of natural dissolved organic-matter at the oxide water interface. Geochim Cosmochim Acta 46: 2381-2393. https://doi.org/10.1016/0016-7037(82)90209-5

Davis SE, Corronado-Molina C, Childers DL, Day JW (2003) Temporally dependent $\mathrm{C}, \mathrm{N}$, and $\mathrm{P}$ dynamics associated with the decay of Rhizophora mangle L. leaf litter in oligotrophic mangrove wetlands of the Southern Everglades. Aquat Bot 75: 199-215. https://doi.org/10.1016/s0304-3770(02)00176-6

Dittmar T, Hertkorn N, Kattner G, Lara RJ (2006) Mangroves, a major source of dissolved organic carbon to the oceans. Global biogeochemical cycles 20. https://doi.org/10.1029 $12005 \mathrm{gb} 002570$

Donato DC, Kauffman JB, Murdiyarso D, Kurnianto S, Stidham M, Kanninen M (2011) Mangroves among the most carbonrich forests in the tropics. Nat Geosci 4:293-297. https://doi. org/10.1038/ngeo1123

Fierer N, Schimel JP, Cates RG, Zou JP (2001) Influence of balsam poplar tannin fractions on carbon and nitrogen dynamics in Alaskan taiga floodplain soils. Soil Biol Biochem 33:18271839. https://doi.org/10.1016/s0038-0717(01)00111-0

Gabler CA, Osland MJ, Grace JB, Stagg CL, Day RH, Hartley SB, Enwright NM, From AS, McCoy ML, McLeod JL (2017) Macroclimatic change expected to transform coastal wetland ecosystems this century. Nat Clim Chang 7:227. https://doi. org/10.1038/nclimate3232

Gamble GR, Akin DE, Makkar HPS, Becker K (1996) Biological degradation of tannins in sericea lespedeza (Lespedeza cuneta) by the white rot fungi Ceriporiopsis subvermispora and Cyathus stercoreus analyzed by solid-state ${ }^{13} \mathrm{C}$ nuclear magnetic resonance spectroscopy. Appl Environ Microbiol 62:3600-3604

Grant WD (1976) Microbial degradation of condensed tannins. Science 193:1137-1139. https://doi.org/10.1126/science.959828

Halvorson JJ, Gonzalez JM, Hagerman AE (2011) Repeated applications of tannins and related phenolic compounds are retained by soil and affect cation exchange capacity. Soil
Biol Biochem 43:1139-1147. https://doi.org/10.1016/j. soilbio.2011.01.023

Hartzfeld PW, Forkner R, Hunter MD, Hagerman AE (2002) Determination of hydrolyzable tannins (gallotannins and ellagitannins) after reaction with potassium iodate. J Agric Food Chem 50:1785-1790. https://doi.org/10.1021/jf0111155

Hattenschwiler S, Vitousek PM (2000) The role of polyphenols in terrestrial ecosystem nutrient cycling. Trends Ecol Evol 15: 238-243. https://doi.org/10.1016/s0169-5347(00)01861-9

Hauser AS (2006) Distichlis spicata. Fire effects information system, [online]. U.S. Department of Agriculture, Forest Service, Rocky Mountain Research Station, fire sciences laboratory

Hernes PJ, Hedges JI (2004) Tannin signatures of barks, needles, leaves, cones, and wood at the molecular level. Geochim Cosmochim Acta 68:1293-1307. https://doi.org/10.1016/j. gca.2003.09.015

Hernes PJ, Benner R, Cowie GL, Goni MA, Bergamaschi BA, Hedges JI (2001) Tannin diagenesis in mangrove leaves from a tropical estuary: a novel molecular approach. Geochim Cosmochim Acta 65:3109-3122. https://doi.org/10.1016 /s0016-7037(01)00641-x

Hingston FJ (1963) Activity of polyphenolic constituents of leaves of Eucalyptus and other species in complexing and dissolving iron oxide. Aust J Soil Res 1:63-73. https://doi. org/10.1071/SR9630063

Kaal J, Nierop KGJ, Verstraten JM (2005) Retention of tannic acid and condensed tannin by Fe-oxide-coated quartz sand. J Colloid Interface Sci 287:72-79. https://doi.org/10.1016/j. jcis.2005.01.104

Kaiser K (2003) Sorption of natural organic matter fractions to goethite (alpha-FeOOH): effect of chemical composition as revealed by liquid-state C-13 NMR and wet-chemical analysis. Org Geochem 34:1569-1579. https://doi.org/10.1016 /s0146-6380(03)00120-7

Kandil FE, Grace MH, Seigler DS, Cheeseman JM (2004) Polyphenolics in Rhizophora mangle L. leaves and their changes during leaf development and senescence. TreesStructure and Function 18:518-528. https://doi.org/10.1007 /s00468-004-0337-8

Kanerva S, Kitunen V, Kiikkila O, Loponen J, Smolander A (2006) Response of soil C and N transformations to tannin fractions originating from scots pine and Norway spruce needles. Soil Biol Biochem 38:1364-1374. https://doi. org/10.1016/j.soilbio.2005.10.013

Keuskamp JA, Schmitt H, Laanbroek HJ, Verhoeven JTA, Hefting MM (2013) Nutrient amendment does not increase mineralisation of sequestered carbon during incubation of a nitrogen limited mangrove soil. Soil Biol Biochem 57:822829. https://doi.org/10.1016/j.soilbio.2012.08.007

Keuskamp JA, Feller IC, Laanbroek HJ, Verhoeven JTA, Hefting MM (2015) Short- and long-term effects of nutrient enrichment on microbial exoenzyme activity in mangrove peat. Soil Biol Biochem 81:38-47. https://doi.org/10.1016/j.soilbio.2014.11.003

Kiem R, Kogel-Knabner I (2002) Refractory organic carbon in particle-size fractions of arable soils II: organic carbon in relation to mineral surface area and iron oxides in fractions $<6 \mu \mathrm{m}$. Org Geochem 33:1699-1713. https://doi. org/10.1016/s0146-6380(02)00112-2

Kraus TEC, Dahlgren RA, Zasoski RJ (2003) Tannins in nutrient dynamics of forest ecosystems - a review. Plant Soil 256:4166. https://doi.org/10.1023/a:1026206511084 
Kraus TEC, Zasoski RJ, Dahlgren RA, Horwath WR, Preston CM (2004) Carbon and nitrogen dynamics in a forest soil amended with purified tannins from different plant species. Soil Biol Biochem 36:309-321. https://doi.org/10.1016/j. soilbio.2003.10.006

Kristensen E, Bouillon S, Dittmar T, Marchand C (2008) Organic carbon dynamics in mangrove ecosystems: a review. Aquat Bot 89:201-219. https://doi.org/10.1016/j. aquabot.2007.12.005

Kumar R, Horigome T (1986) Fractionation, characterization, and protein-precipitating capacity of the condensed tannins from Robinia pseudoacacia L leaves. J Agric Food Chem 34:487489. https://doi.org/10.1021/jf00069a029

Laanbroek HJ, Zhang QF, Leite M, Verhoeven JTA, Whigham DF (2018) Effects of Rhizophora mangle leaf litter and seedlings on carbon and nitrogen cycling in salt marshes - potential consequences of climate-induced mangrove migration. Plant Soil 426:383-400. https://doi.org/10.1007/s11104-0183611-z

Lin YM, Liu JW, Xiang P, Lin P, Ye GF, Sternberg L (2006) Tannin dynamics of propagules and leaves of Kandelia candel and Bruguiera gymnorrhiza in the Jiulong River estuary, Fujian, China. Biogeochemistry 78:343-359. https://doi.org/10.1007/s10533-005-4427-5

Lin YM, Liu XW, Zhang H, Fan HQ, Lin GH (2010) Nutrient conservation strategies of a mangrove species Rhizophora stylosa under nutrient limitation. Plant Soil 326:469-479. https://doi.org/10.1007/s11104-009-0026-x

Maie N, Behrens A, Knicker H, Kogel-Knabner I (2003) Changes in the structure and protein binding ability of condensed tannins during decomposition of fresh needles and leaves. Soil Biol Biochem 35:577-589. https://doi.org/10.1016 /s0038-0717(03)00051-8

Maie N, Pisani O, Jaffe R (2008) Mangrove tannins in aquatic ecosystems: their fate and possible influence on dissolved organic carbon and nitrogen cycling. Limnol Oceanogr 53: 160-171. https://doi.org/10.4319/lo.2008.53.1.0160

Morita H (1980) Total phenolic content in the pyrophosphate extracts of 2 peat soil profiles. Can J Soil Sci 60:291-297

Nierop KGJ, Preston CM, Verstraten JM (2006a) Linking the B ring hydroxylation pattern of condensed tannins to $\mathrm{C}$. $\mathrm{N}$ and P mineralization A case study using four tannins Soil Biology \& Biochemistry 38:2794-2802. https://doi.org/10.1016/j. soilbio.2006.04.049

Nierop KGJ, Verstraten JM, Tietema A, Westerveld JW, Wartenbergh PE (2006b) Short- and long-term tannin induced carbon, nitrogen and phosphorus dynamics in Corsican pine litter. Biogeochemistry 79:275-296. https://doi.org/10.1007/s10533-005-5274-0

Northup RR, Yu ZS, Dahlgren RA, Vogt KA (1995) Polyphenol control of nitrogen release from pine litter. Nature 377:227229. https://doi.org/10.1038/377227a0

Northup RR, Dahlgren RA, McColl JG (1998) Polyphenols as regulators of plant-litter-soil interactions in northern California's pygmy forest: a positive feedback? Biogeochemistry 42:189-220. https://doi.org/10.1023 /a:1005991908504

Rivera-Monroy VH, Twilley RR (1996) The relative role of denitrification and immobilization in the fate of inorganic nitrogen in mangrove sediments (Terminos lagoon, Mexico). Limnol Oceanogr 41:284-296

Saintilan N, Rogers K, McKee K (2009) Salt-marsh-mangrove interactions in Australia and the Americas. In: Perillo GME, Wolanski E, Cahoon DR, Brinson MM (eds) Coastal wetlands: an integrated ecosystem approach. Elsevier, Amsterdam

Saintilan N, Wilson NC, Rogers K, Rajkaran A, Krauss KW (2014) Mangrove expansion and salt marsh decline at mangrove poleward limits. Glob Change Biol 20:147-157. https://doi.org/10.1111/gcb.12341

Schimel JP, Helfer S, Alexander IJ (1992) Effects of starch additions on N-turnover in Sitka spruce forest floor. Plant Soil 139:139-143. https://doi.org/10.1007/bf00012851

Schimel JP, VanCleve K, Cates RG, Clausen TP, Reichardt PB (1996) Effects of balsam poplar (Populus balsamifera) tannins and low molecular weight phenolics on microbial activity in taiga floodplain soil: implications for changes in $\mathrm{N}$ cycling during succession. Can J Bot-Rev Can Bot 74:84 90. https://doi.org/10.1139/b96-012

Schnitzer M, Barr M, Hartenstein R (1984) Kinetics and characteristics of humic acids produced from simple phenols. Soil Biol Biochem 16:371-376. https://doi.org/10.1016/00380717(84)90035-x

Shajeela PS, Mohan VR, Jesudas LL, Soris PT (2011) Nutritional and antinutritional evaluation of wild yam (Dioscorea spp.). Tropical and Subtropical ecosystems 14:723-730

Talbot JM, Finzi AC (2008) Differential effects of sugar maple, red oak, and hemlock tannins on carbon and nitrogen cycling in temperate forest soils. Oecologia 155:583-592. https://doi. org/10.1007/s00442-007-0940-7

Valiela I, Teal JM, Allen SD, Vanetten R, Goehringer D, Volkmann S (1985) Decomposition in salt-marsh ecosystems - the phases and major factors affecting disappearance of above-ground organic-matter. J Exp Mar Biol Ecol 89:2954. https://doi.org/10.1016/0022-0981(85)90080-2

Varadachari C, Mondal AH, Nayak DC, Ghosh K (1994) Clayhumus complexation - effect of $\mathrm{pH}$ and the nature of bonding. Soil Biol Biochem 26:1145-1149. https://doi.org/10.1016 /0038-0717(94)90136-8

Verkaik E, Jongkind AG, Berendse F (2006) Short-term and longterm effects of tannins on nitrogen mineralisation and litter decomposition in kauri (Agathis australis (D. Don) Lindl.) forests. Plant Soil 287:337-345. https://doi.org/10.1007 /s11104-006-9081-8

Zech W, Senesi N, Guggenberger G, Kaiser K, Lehmann J, Miano TM, Miltner A, Schroth G (1997) Factors controlling humification and mineralization of soil organic matter in the tropics. Geoderma 79:117-161. https://doi.org/10.1016 /s0016-7061(97)00040-2

Zhang L-L, Lin Y-M, Zhou H-C, Wei S-D, Chen J-H (2010) Condensed tannins from mangrove species Kandelia candel and Rhizophora mangle and their antioxidant activity. Molecules 15:420-431. https://doi.org/10.3390 /molecules 15010420

Zhou HC, Tam NFY, Lin YM, Wei SD, Li YY (2012) Changes of condensed tannins during decomposition of leaves of Kandelia obovata in a subtropical mangrove swamp in China. Soil Biol Biochem 44:113-121. https://doi. org/10.1016/j.soilbio.2011.09.015 